\title{
Sodium Nitroprusside Evokes the Release of Immunoreactive Calcitonin Gene-Related Peptide and Substance P from Dorsal Horn Slices via Nitric Oxide-Dependent and Nitric Oxide-Independent Mechanisms
}

\author{
Mary G. Garry, ${ }^{1, a}$ Jennelle Durnett Richardson, ${ }^{1,2}$ and Kenneth M. Hargreaves ${ }^{1,2}$ \\ ${ }^{1}$ Department of Restorative Sciences, and 'Department of Pharmacology, University of Minnesota Dental School, \\ Minneapolis, Minnesota 55455
}

The results of behavioral studies suggest that nitric oxide (NO) participates in certain spinal mechanisms that contribute to hyperalgesia. Additionally, previous studies indicate that the release of immunoreactive calcitonin gene-related peptide (iCGRP) and substance P (iSP) is increased in the dorsal horn of the spinal cord during hyperalgesia. Therefore, the aim of this study was to determine whether NO acts to enhance peptide release in the dorsal horn of rats using an in vitro superfusion technique. Sodium nitroprusside (SNP) was used as an NO donor. The results of this study indicate that SNP caused a dose-related, calcium-dependent increase in the release of iCGRP and iSP from dorsal horn slices of the rat spinal cord. Furthermore, pretreatment with SNP reduced the ability of capsaicin to evoke the release of either peptide, suggesting that a target for SNP exists on certain capsaicin-sensitive primary afferent terminals. In addition to increasing peptide release, SNP also caused a significant five to sixfold increase in the levels of immunoreactive guanosine $3^{\prime}, 5^{\prime}$-monophosphate (i-cGMP) in the dorsal horn. This SNP-evoked increase was significantly decreased by the guanylate cyclase inhibitor methylene blue in a dosedependent manner. In addition, the release of iCGRP was also significantly reduced in the presence of methylene blue, although the relationship between peptide release and i-cGMP production remains unclear. Sodium nitroprussideevoked peptide release was significantly reduced in the presence of hemoglobin (an oxide radical scavenger), suggesting that the drug effect was due to the generation of NO. However, the release of iCGRP and iSP was also evoked by sodium ferricyanide (the coproduct of SNP) and by 7-d-old, photoinactivated SNP. Taken together, these data indicate that SNP acts to evoke the release of iCGRP and iSP from primary afferent neurons in the dorsal horn. In addition, these data suggest that the SNP-evoked increase in iCGRP release may be associated with increasing tissue levels of i-cGMP.

\footnotetext{
Received July 8, 1993; revised Dec. 10, 1993; accepted Jan. 20, 1994.

Correspondence should be addressed to Kenneth M. Hargreaves, DDS, Ph.D. University of Minnesota Dental School, Department of Restorative Sciences, 8-166 Moos Tower, 515 Delaware Street SE, Minneapolis, MN 55455.

aresent address: University of Texas Southwestern Medical Center, Department of Anesthesiology and Pain Research, 3323 Harry Hines Boulevard, Dallas, TX 75235 .

Copyright (C) 1994 Society for Neuroscience $0270-6474 / 94 / 144329-09 \$ 05.00 / 0$
}

Finally, these data indicate that SNP has NO-dependent and NO-independent mechanisms of action in the dorsal horn.

[Key words: nitric oxide, sodium nitroprusside, spinal cord, substance $P$, calcitonin gene-related peptide, cGMP]

\section{Hyperalgesia and central sensitization}

Hyperalgesia is a condition that is characterized by decreased pain thresholds, increased pain to suprathreshold stimuli and, at times, spontaneous pain (Campbell and Meyer, 1986). While peripheral mechanisms for hyperalgesia have been established, central mechanisms are also critical for the development of hyperalgesia (Simone et al., 1991; Simone, 1992; Treede et al., 1992; Grubb et al., 1993). A major mechanism that is believed to underlie the development of hyperalgesia is termed central sensitization. In general, central sensitization is characterized by the hyperexcitability of dorsal horn neurons at the level of the spinal cord. In animals with polyarthritis (involvement of both the hindpaw and ankle), wide-dynamic-range (WDR) and nociceptive-specific neurons exhibit enhanced spontaneous firing (Menetrey and Besson, 1982). In addition, these neurons show an increased discharge response to innocuous and noxious stimulation (Schiable et al., 1987). This progressive increase in the discharge of dorsal horn neurons in response to a stimulus of constant intensity is termed "wind-up" (Davies and Watkins, 1983). Finally, dorsal horn neurons have expanded receptive fields during inflammation (Hylden et al., 1989), and therefore receive a greater afferent input when compared to dorsal horn neurons from normal animals. It has been proposed that these changes in the response properties of dorsal horn neurons are believed to be the result of synaptic plasticity and are thought to resemble the synaptic strengthening that facilitates the process of learning and memory (Meller and Gebhart, 1993).

\section{Nitric oxide is a novel neuronal messenger}

Evidence is rapidly growing in support of the role of nitric oxide (NO) as a neuronal messenger in the nervous system (Moncada et al., 1991a; Bredt and Snyder, 1992; McCall and Vallance, 1992). In the cerebellum, biochemical analyses have shown that NO, either exogenously applied or endogenously generated, activates the soluble form of guanylate cyclase, probably through a series of reduction-oxidation events where NO binds to the heme moiety of the guanylate cyclase molecule (Waldman and Murad, 1987; Southam et al., 1991). This activation of guanylate cyclase results in the generation of guanosine $3^{\prime}, 5^{\prime}$-cyclic mono- 
phosphate (cGMP). This increase in cGMP has been observed to mediate many of the effects of NO in the CNS (Garthwaite, 1991; McCall and Vallance, 1992). One major role that has been defined for NO is the mediation of learning and memory at the level of the hippocampus (Malenka et al., 1988, 1989; Chapman et al., 1992; Haley et al., 1992b).

\section{Nitric oxide and hyperalgesia}

It has recently been suggested that NO may, under certain conditions, play a role in the development of hyperalgesia. In support of this, behavioral data suggest that NMDA-evoked hyperalgesia is mediated via NO (Kitto et al., 1992; Meller et al., 1992). Intrathecal administration of NMDA produces a rapid, dose-related, thermal hyperalgesia in mice and rats (Aanonsen and Wilcox, 1987; Meller et al., 1992a), which is blocked by pretreatment with a selective NMDA antagonist, AP5 (Kolhkear et al., 1992; Meller et al., 1992a). This NMDA-induced hyperalgesia is also abolished by pretreatment with $\mathrm{N}^{\mathrm{G}}$-nitroL-arginine methyl ester (L-NAME; a competitive inhibitor of NOS) (Kitto et al., 1992; Meller et al., 1992a), methylene blue (a guanylate cyclase inhibitor) (Meller et al., 1992a), and hemoglobin (a superoxide anion scavenger) (Kitto et al., 1992). In a similar study, it was suggested that the hyperalgesia that occurs during pcripheral neuropathy is dependent upon the production of NO in the spinal cord (Meller et al., 1992b). Additionally, electrophysiological studies indicate that NO has a role in prolonged chemical nociception in the rat (Haley et al., 1992a). Taken together, the results of these behavioral studies suggest that NMDA-induced hyperalgesia is mediated by an NO-cGMPdependent pathway.

A number of pharmacological tools are now available to probe the functions of the NO-cGMP pathway, including inhibitors of NO synthesis, superoxide anion scavengers, and guanylate cyclase inhibitors, as described above. In addition, the family of nitrovasodilator drugs are NO donors. These drugs donate NO either spontaneously or enzymatically. Sodium nitroprusside (SNP) spontaneously generates NO and has been demonstrated to be a potent agent for stimulating the production of immunoreactive cGMP (i-cGMP) in cerebellar slices (Southam and Garthwaite, 1991). This drug provides a practical way to apply NO to tissues. In addition, the kinetics of NO release have been determined from SNP, and therefore, the concentration of NO formation following the administration of SNP can be calculated (Knowles et al., 1990).

It was previously demonstrated that the release of immunoreactive calcitonin gene-related peptide (iCGRP) and substance $\mathrm{P}$ (iSP) is increased in the dorsal horn of the spinal cord in various species during hyperalgesia (Oku et al., 1987a,b; Nanayama et al., 1989; Schiable et al., 1990; Garry and Hargreaves, 1992). In addition, both CGRP and SP have previously been implicated as having a role in nociceptive processing at the level of the spinal cord (Bossut et al., 1988; Kawamura et al., 1989; Tsai et al., 1989; Otsuka and Yangisawa, 1990; Coderre and Melzack, 1991; Murray et al., 1991; Sun and Larson, 1991; Galeazza et al., 1992; Satoh et al., 1992; Sluka et al., 1992). As a result, we have hypothesized that the enhanced release of iCGRP and iSP from the dorsal horn may be a biochemical marker for the development of hyperalgesia (Garry and Hargreaves, 1992).

Therefore, the aim of this study was to determine whether NO facilitates hyperalgesia at the level of the spinal cord by enhancing the release of peptides in the dorsal horn. To achieve this, we measured the release of iCGRP and iSP from the spinal dorsal horn of the rat in response to SNP using an in vitro superfusion technique. We also measured the levels of i-cGMP in dorsal horn slices following stimulation with SNP. Finally, we evaluated whether the effects of SNP on peptide release and i-cGMP levels were selectively due to the spontaneous generation of NO.

\section{Materials and Methods}

Spinal cord superfusion and measurement of iCGRP and iSP. Male Sprague-Dawley rats (175-199 gm, Harlan Company, Madison, WI) were housed in our animal care facility for 1 week following delivery with $12 \mathrm{hr}$ light/dark cycles and received food and water ad lib. All procedures were approved by the ACUC at the University of Minnesota. On the day of the experiment, rats were decapitated and the spinal cords were removed by hydraulic extrusion using ice-cold Krebs buffer. The lumbar enlargement was isolated and the ventral half of the spinal cord was removed and discarded. The dorsal half of the spinal cord was placed on a McIlwain tissue chopper (Mickle Laboratory Engineering Co., Gomshall, UK) and $200 \mu \mathrm{m}$ cubes were prepared. The tissue was placed into $1 \mathrm{cc}$ chambers, which were pumped $(0.5 \mathrm{ml} / \mathrm{min})$ with oxygenated Krebs buffer $[\mathrm{NaCl}(135 \mathrm{~mm}), \mathrm{KCl}(3.5 \mathrm{~mm}), \mathrm{MgCl}(1 \mathrm{~mm})$, $\mathrm{NaH}_{2} \mathrm{PO}_{4}(1 \mathrm{~mm}), \mathrm{NaHCO}_{3}(20 \mathrm{~mm}), \mathrm{CaCl}_{2}(2.5 \mathrm{~mm})$, bovine serum albumin $(0.1 \%)$, dextrose $(3.3 \mathrm{~mm})$, bacitracin $(3 \%)$, ascorbic acid $(0.1$ $\mathrm{mm})$, thiorphan $(0.01 \mathrm{~mm}) \mathrm{pH} 7.4$ at $\left.37^{\circ} \mathrm{C}\right]$. Fractions were collected every 3 min throughout the experiment into tubes containing $100 \mu \mathrm{l}$ of 1 м MES (Sigma Chemical Co., St. Louis, MO), which maintained the $\mathrm{pH}$ of the fractions at 6.1. Each fraction was divided for radioimmunoassay (RIA) of iCGRP and iSP. The CGRP antiserum (MI-C2, kindly provided by Dr. M. Iadarola) binds near the C-terminal end of CGRP but does not cross-react with cholecystokinin, neuropeptide $\mathrm{Y}$, or other peptides with similar C-terminal residues such as FMRFamide peptides. The CGRP antiserum detected amylin but only at concentrations that were 3 orders of magnitude in excess of the minimal detectable concentration of CGRP. The SP antiserum (SP-1, kindly provided by Dr. S. Leeman) binds near the C-terminal sequence of the peptide, and has no cross-reactivity with 100 pmol of substance $\mathrm{K}$, physalaemin, metenkephalin, or eledoisin. Under nonequilibrium conditions, the minimum detection limit for these assays is approximately $1 \mathrm{fmol} /$ tube, with $50 \%$ displacements at 10-20 fmol/tube. The inter- and intraassay coefficients of variations are less than $6 \%$ and $12 \%$, respectively. All drugs used in these experiments were evaluated for possible interference in the RIAs. The antibody-antigen complex was separated from the free tracer using an immunomagnetic precipitation technique (Advanced Magnetics Inc., Cambridge, MA).

Drugs. Sodium nitroprusside (SNP), hemoglobin, and methylene blue, were purchased from Sigma Chemical Co. (St. Louis, MO). Capsaicin and sodium ferricyanide were purchased from Fluka (Ronkonkoma, NY).

Effects of SNP on spontaneous and capsaicin-evoked peptide release. Following an equilibration period in Kreb's buffer ( $36 \mathrm{~min}$ ), the tissue was superfused with SNP [1-100 mM $(n=4-6 /$ dose $)]$ for $21 \mathrm{~min}$ to evaluate the effect of SNP on peptide release. Based on the studies of Knowles et al. (1990), these doses of SNP generate 1-100 $\mu \mathrm{M} \mathrm{NO} / \mathrm{min}$.

To determine whether the effects of sodium nitroprusside were calcium dependent, we evaluated peptide release following superfusion with the highest dose of SNP in the absence of calcium. Following a 36 min equilibration period, the tissues were superfused with SNP (100 $\mathrm{mm} ; 21 \mathrm{~min}$ stimulation period) in the presence $(n=5)$ or absence $(n$ $=5$ ) of calcium. The $\mathrm{Ca}^{2+}$-free Kreb's buffer also contained $10 \mathrm{~mm}$ EGTA to chelate endogenous calcium.

To determine whether SNP activated a subclass of small-diameter afferent fibers in the dorsal horn, wc cvaluatcd the cffect of SNP pretreatment on capsaicin-evoked release of iCGRP and iSP as previously described (Garry and Hargreaves, 1992). Following the equilibration period, dorsal horn slices were superfused with either (1) capsaicin (10 $\mu \mathrm{M}, n=6$ ) for $6 \mathrm{~min},(2) \mathrm{SNP}(3-100 \mathrm{mM}, n=4-6 /$ dose) for $21 \mathrm{~min}$, or (3) SNP (3-100 mM, $n=4-6 /$ dose) for $21 \mathrm{~min}$ prior to and during a stimulation with capsaicin $(10 \mu \mathrm{M}, 6 \mathrm{~min})$. Capsaicin selectively excites a subclass of small-diameter primary afferent terminals (C- and some A $\delta$-type fibers) (Fitzgerald, 1983).

Effect of a guanylate cyclase inhibitor on peptide release and $i-c G M P$ levels. In order to determine whether SNP-evoked effects on peptide 
release could be attributed to the activation of guanylate cyclase, we attempted to block the effects of SNP on peptide release by superfusing the tissue with methylene blue [a known guanylate cyclase inhibitor (Waldman and Murad, 1987)]. Following an equilibration period, tissues were superfused with either (1) Kreb's buffer only $(n=7),(2)$ methylene blue only ( $10 \mu \mathrm{M}, n=8)$ for $21 \mathrm{~min}$, (3) SNP only (30 or $100 \mathrm{~mm}, n=8-14 /$ dose) for $12 \mathrm{~min}$, or (4) methylene blue (10 or 100 $\mu \mathrm{M}, n=8-14 /$ dose) for 9 min prior to and during a stimulation with SNP ( 30 and $100 \mathrm{~mm}$ ) for $12 \mathrm{~min}$. Following the superfusion experiment, the tissue levels of $i$-cGMP were assessed. Tissues were removed from the chamber and cGMP extraction was performed by boiling the tissue for $3 \mathrm{~min}$ in a $50 \mathrm{~mm}$ Tris, $4 \mathrm{~mm}$ EGTA buffer $(\rho \mathrm{H} \mathrm{7.6)}$ as has been previously described (Southam and Garthwaite, 1991). Following boiling, the tissue was sonicated and centrifuged and the supernatants were acetylated and assayed for immunoreactive cGMP (i-cGMP) using a commercially available RIA (Peninsula Laboratories, Belmont, CA).

Evaluation of the NO-dependent and-independent mechanisms of SNP. To determine whether the effects of SNP were mediated by the generation of NO, we attempted to block the effects of SNP on peptide release and i-cGMP by pretreating the tissue with hemoglobin. Nitric oxide binds to the heme moieties of guanylate cyclase and hemoglobin. Therefore, in the presence of excess hemoglobin, extracellular nitric oxide is bound, reducing the levels of NO that are available to bind to guanylate cyclase (Moncada et al., 1991b). Following an equilibration period, tissues were superfused with either (1) Kreb's buffer only $(n=8),(2)$ SNP (100 mM, $n=8$ ) for $18 \mathrm{~min}$, or (3) hemoglobin $(3$ or $10 \mathrm{mg} / \mathrm{ml}$, $n=10-12 /$ dose) prior to and during a stimulation with SNP $(100 \mathrm{~mm}$; $18 \mathrm{~min}$ ). Following this superfusion experiment, the tissue from each chamber was prepared for assessment of i-cGMP as described above.

To evaluate further the contribution of NO to the SNP-evoked effect, we superfused dorsal horn slices with SNP that had been prepared 1 week in advance of the experimental day. SNP was dissolved in sterile Kreb's buffer, and stored at room temperature under ultraviolet light for 1 week. Based on the known kinetics of this drug and the half-life of NO (Knowles et al., 1990), we calculated that no nitric oxide should be present in the preparation when it has been in solution for $7 \mathrm{~d}$ (i.e, a time equal to 20 half-lives of SNP dissolution). Following an equilibration period, tissues were superfused with either (1) Kreb's buffer ( $n$ $=8)$, (2) fresh SNP ( $100 \mathrm{~mm}, n=6)$ for $18 \mathrm{~min}$, or (3) 1-week-old SNP $(100 \mathrm{~mm}, n=7)$ for $18 \mathrm{~min}$. Following this superfusion experiment, the tissue from each chamber was prepared for assessment of $i$-cGMP as described above.

The products of SNP breakdown are sodium ferricyanide and NO (Southam and Garthwaite, 1991). Therefore, we further evaluated the selectivity of SNP by determining the effect of sodium ferricyanide on peptide release and i-cGMP levels. Following an equilibration period, tissues were superfused with either (1) normal Kreb's buffer $(n=8),(2)$ SNP (100 mM, $n=4-6)$, or (3) sodium ferricyanide (100 mM, $n=4-$ 6) for $18 \mathrm{~min}$. Following this superfusion experiment, the tissue from each chamber was prepared for assessment of i-cGMP as described above.

Statistics. All superfusion data is presented as a sum score (mean \pm SEM), determined by calculating total peptide release over consecutive fractions. $A_{50}$ values were calculated using PHARM/PCs Software (Microcomputer Specialists). The $A_{50}$ value is defined as the concentration of a drug that produces a $50 \%$ effect of a graded response; in this case, the $A_{50}$ dose is the concentration of SNP that evokes $50 \%$ of maximal secretion of either iSP or iCGRP. In thesc studies, maximal secretion of iCGRP or iSP is defined by the release of each peptide in the presence of $10 \mu \mathrm{M}$ capsaicin. The results from the $\mathrm{i}$-cGMP assays are presented as $\mathrm{pmol} / \mathrm{gm}$ wet weight (mean \pm SEM). One-way and multiway ANOVAs were performed to analyze experiments according to experimental design. Post hoc tests were used to determine the source of statistical differences between various groups (Duncan's or Tukey's) or relative to the control group (Dunnett's). When the experimental design only included two groups, a Student's $t$ test was performed to evaluate whether differences between groups were statistically significant. The level of significance was $p<0.05$.

\section{Results}

Effects of SNP on spontaneous and capsaicin-evoked peptide release

Basal levels of release of iCGRP (Fig. 1A; $3412 \pm 247 \mathrm{fmol} /$ $\mathrm{gm} / 9 \mathrm{~min}$ ) and iSP (Fig. $1 B ; 578 \pm 93 \mathrm{fmol} / \mathrm{gm} / 9 \mathrm{~min}$ ) were

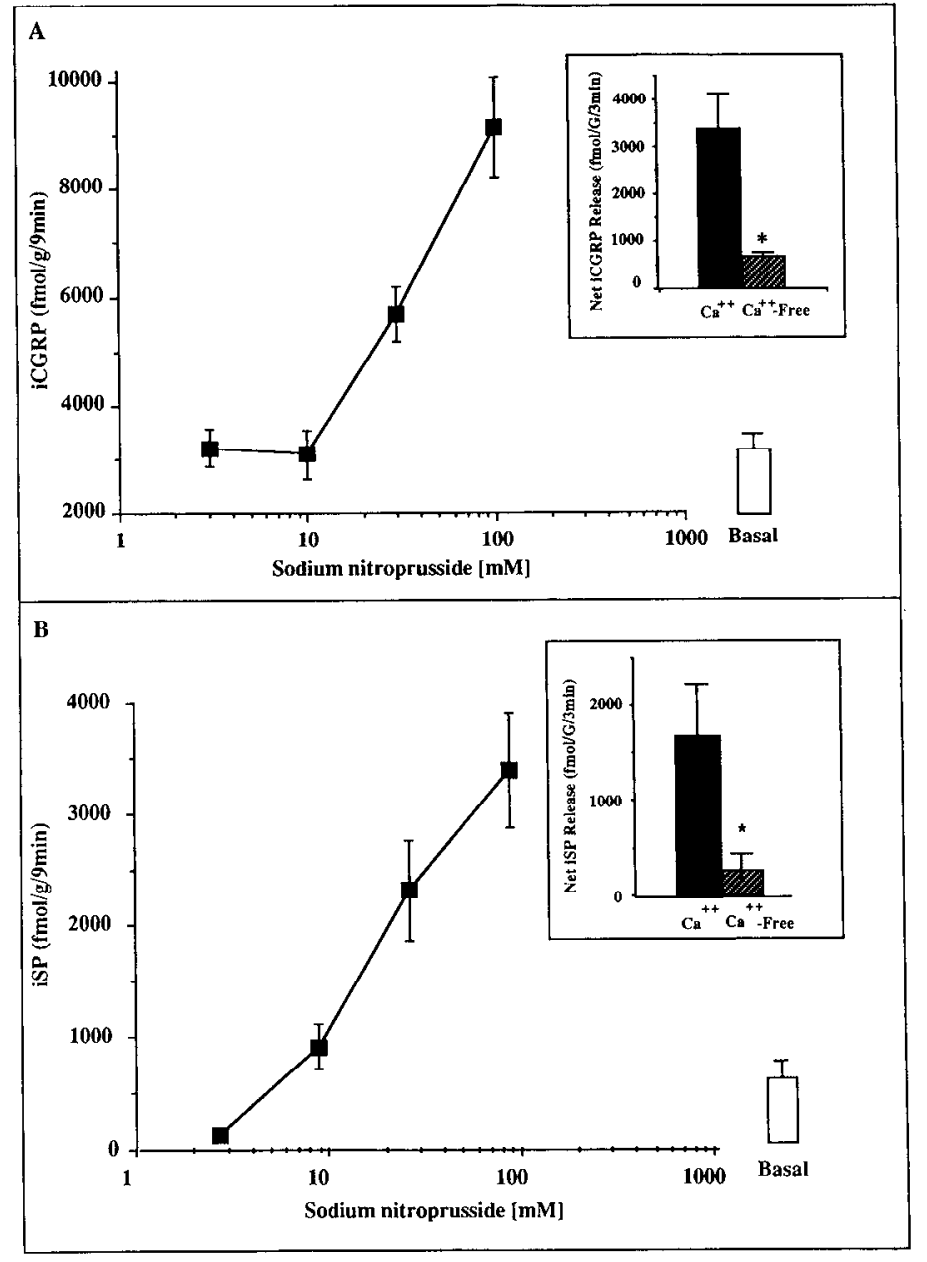

Figure 1. The dose-response curve for the effect of SNP on the release of iCGRP $(A)$ and iSP $(B)$ from rat dorsal horn slices. Peptide release is expressed as a sum of three fractions immediately following a treatment. The open bar represents the basal release of peptide in the presence of Kreb's buffer only. Following superfusion with Kreb's buffer, the tissues were superfused with SNP $[1-100 \mathrm{~mm}(n=4-6 /$ dose $)]$. Insets illustrate the calcium dependence of the SNP-evoked peptide release (100 mM SNP). The solid bars illustrate peptide release in the presence of calcium $(n=5)$ and the hatched bars represent peptide release in the absence of calcium $(n=5)$. Peptide release is expressed as net release, which is calculated by subtracting the basal release from the SNP-evoked release. ${ }^{*}, p<0.05$.

detectable. Sodium nitroprusside caused a dose-related increase in the release of iCGRP (Fig. $1 A$ ) and iSP (Fig. $1 B$ ) from dorsal horn slices. At the highest dose examined, SNP caused a 5.4fold increase in the release of iCGRP and a 4.9 -fold increase in the release of iSP, as compared to basal levels. The $A_{50}$ value of SNP-evoked release of iCGRP was $30.7 \pm 1.2 \mathrm{~mm}$. The $A_{50}$ value of SNP-evoked release of iSP was $30.3 \pm 3.98 \mathrm{~mm}$.

To evaluate the possibility that SNP-evoked release of iCGRP and iSP was due to a nonexocytotic mechanism, we determined the ability of SNP to evoke peptide release in the absence of calcium. Dorsal horn slices that were superfused in the absence of calcium showed a significant reduction in the SNP-cvoked release of iCGRP (Fig. $1 A$, inset) and iSP (Fig. $1 B$, inset) when compared to the SNP-evoked release of peptides in the presence of calcium $(p<0.05)$.

We next evaluated the effect of SNP pretreatment on capsa- 


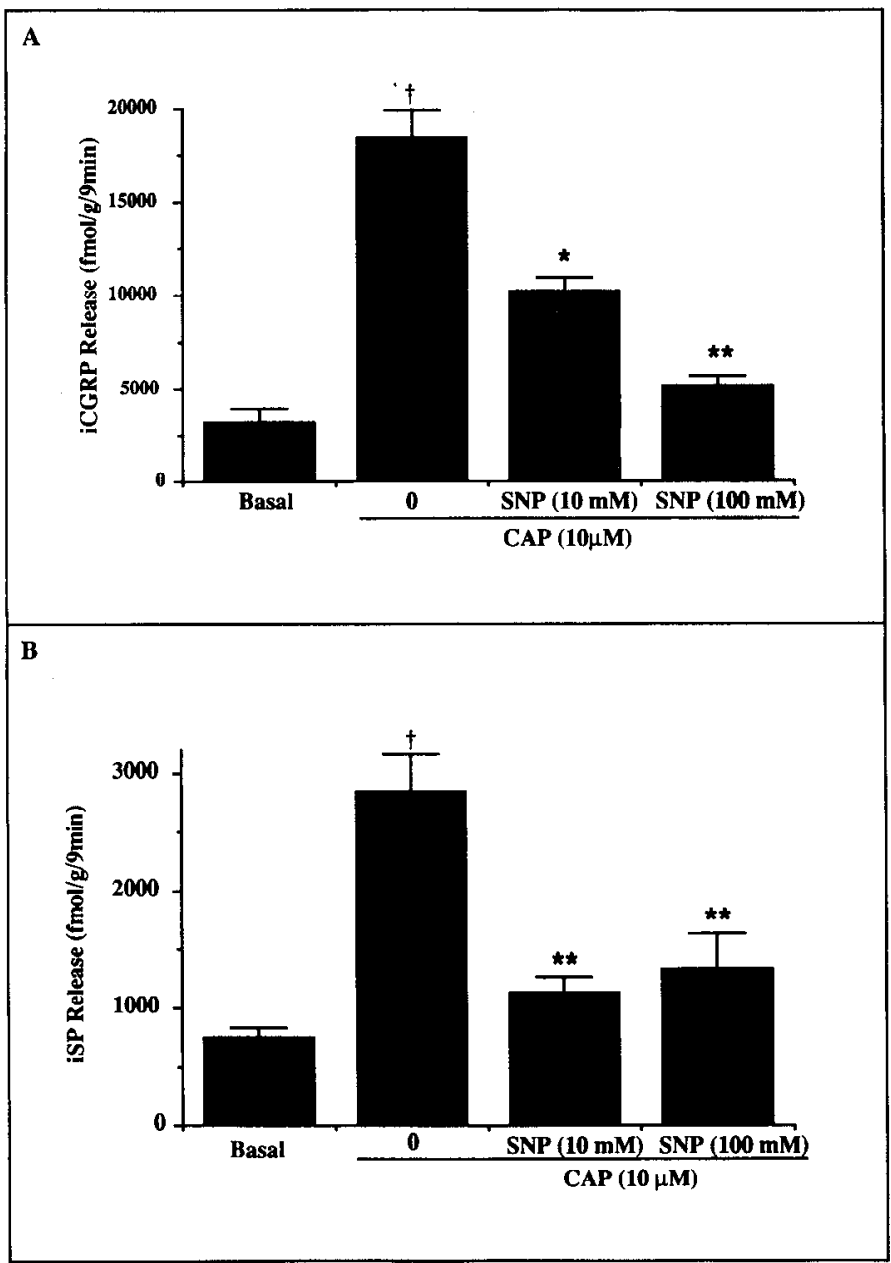

Figure 2. The effect of SNP pretreatment on the release of iCGRP $(A)$ and iSP $(B)$ from dorsal horn slices. Peptide release is expressed as a sum of three fractions immediately following a treatment. The basal release (spontaneous peptide release in response to Kreb's buffer only) is the mean basal release of all the treatment groups that were not significantly different. Following superfusion with Kreb's buffer, tissues were superfused with either (1) capsaicin $(C A P)(n=6)$ or (2) SNP prior to and during capsaicin stimulation $(n=4-6 /$ dose). $\dagger, p<0.01$ versus basal release. ${ }^{*}, p<0.05 ;{ }^{* *}, p<0.01$; versus CAP treatment alone.

icin-evoked release of iCGRP and iSP from dorsal horn slices. Figure $2 A$ illustrates that $10 \mu \mathrm{M}$ capsaicin was efficacious in increasing the release of iCGRP over basal levels $(p<0.01)$. However, administration of SNP prior to and during the capsaicin pulse significantly reduces the ability of capsaicin to evoke the release of iCGRP from dorsal horn slices $[F(3,27)=35.97$, $p<0.01$ ]. Similarly, Figure $2 B$ illustrates that $10 \mu \mathrm{M}$ capsaicin was efficacious in increasing the release of iSP over basal levels $(p<0.01)$. SNP pretreatment also decreases the ability of capsaicin to evoke the release of iSP from dorsal horn slices $[F(3,27)$ $=19.97, p<0.05]$.

\section{Does SNP alter the levels of $i-c G M P$ in the dorsal horn of the spinal cord?}

Figure 3 illustrates that administration of SNP causes a significant increase in the levels of i-cGMP in the dorsal horn of the spinal cord $[F(2,27)=99.02, p<0.01]$. While we observed no detectable increase in the levels of $i$-cGMP following stimulation with $30 \mathrm{~mm}$ SNP, i-cGMP levels were increased approximately

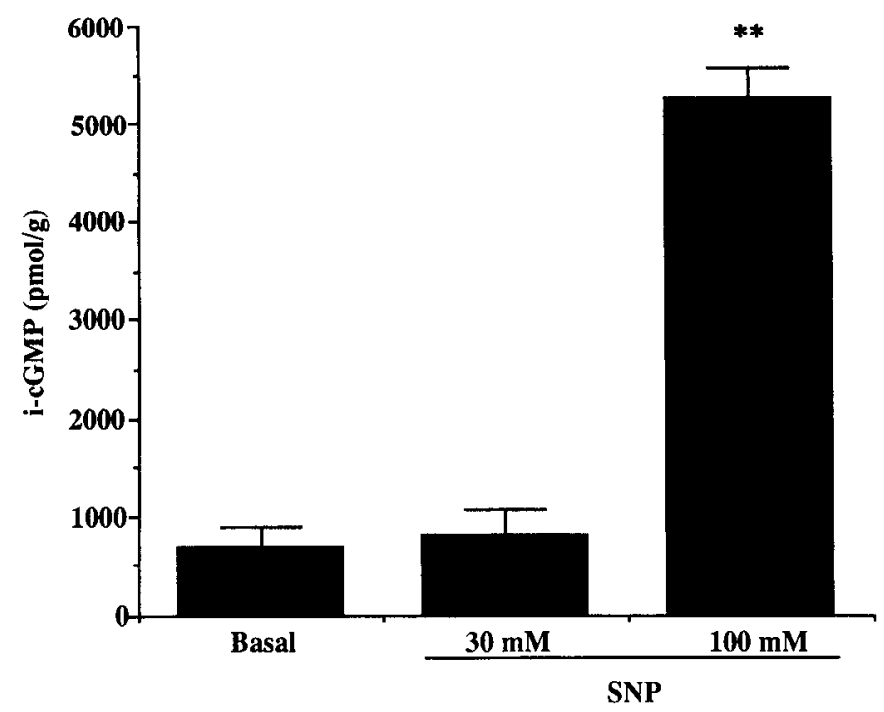

Figure 3. The effect of SNP on tissues levels of i-cGMP in dorsal horn slices. The bar labeled Basal represents the levels of i-cGMP in the presence of Kreb's buffer only. Tissues were superfused with either (1) Kreb's buffer $(n=6)$ or (2) SNP (30 or $100 \mathrm{~mm}, n=6-8 /$ dose). ${ }^{* *}, p$ $<0.01$ versus basal levels.

10-fold over basal levels following stimulation with $100 \mathrm{~mm}$ SNP.

Are the SNP-evoked effects on peptide release related to its effect on $i$-cGMP?

In order to evaluate whether the effect of SNP on peptide release was related to the SNP-evoked increase in i-cGMP, we determined the effect of methylene blue on the level of i-cGMP and peptide release in dorsal horn slices. Figure 4 illustrates that $100 \mathrm{~mm}$ SNP was efficacious in increasing the tissue levels of i-cGMP in the dorsal horn. Importantly, this SNP-evoked increase in the level of $i-c G M P$ was reduced by methylene blue in a dose-related fashion $[F(5,32)-93.63, p<0.001]$. The SNP effect on tissue levels of i-cGMP is completely blocked by pretreatment with methylene blue at concentrations of 10 and 30 mM. Methylene blue alone, at any concentration, had no effect on the level of $\mathrm{i}$-cGMP.

Figure $5 A$ demonstrates that methylene blue, at concentrations greater than $10 \mu \mathrm{M}$, also produces a dose-related blockade of the SNP-evoked release of iCGRP from dorsal horn slices $[F(5,53)=10.61, p<0.01]$, although, the $10 \mu \mathrm{M}$ dose produced a significant increase in iCGRP release when compared to the effect of SNP alone $(p<0.01)$. When the dose of methylene blue was increased to 10 and $30 \mathrm{~mm}$, however, there was a significant suppression of SNP-evoked iCGRP release $(p<0.01)$.

Figure $5 B$ illustrates that $10 \mu \mathrm{M}$ methylene blue was not effective in reducing the release of iSP. We superfused the tissues with higher concentrations of methylene blue; however, control cxperiments indicated that these higher concentrations of methylene blue significantly reduced the ability of the SP antibody to bind to its antigen in our RIA. Therefore, the amount of iSP that was released, in the presence of methylene blue, could not be analyzed with accuracy by our RIA method.

Are the effects of SNP selectively due to the generation of NO? Hemoglobin. To evaluate whether the SNP-evoked effects were selective to the generation of a superoxide anion, the effects of 


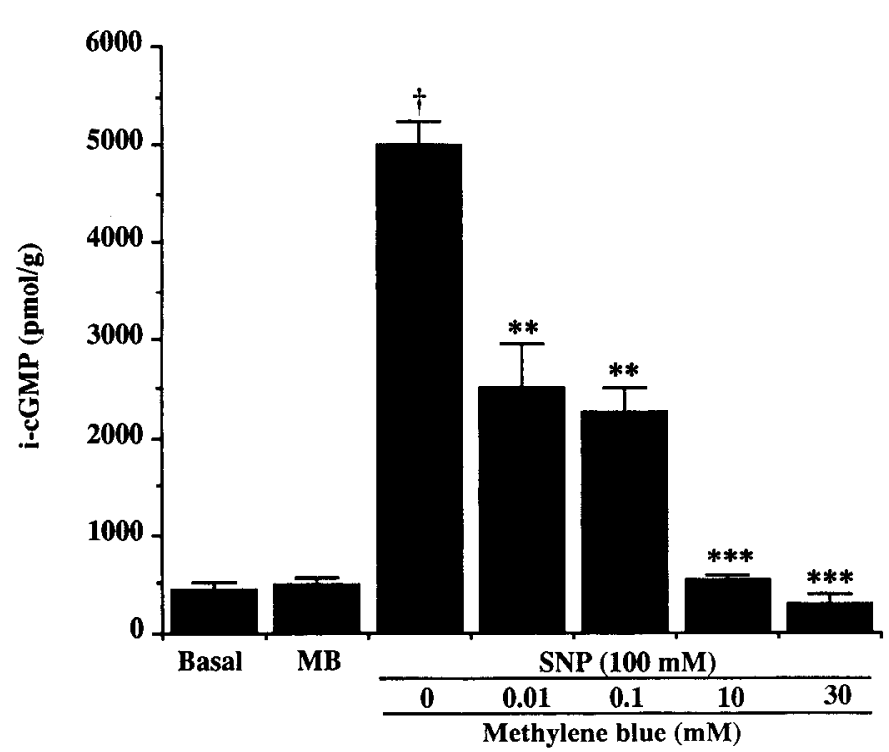

Figure 4. The effect of methylene blue $(M B)$ on the SNP-evoked increase in i-cGMP levels in dorsal horn slices. The basal level refers to $\mathrm{i}$-cGMP levels in the presence of Kreb's buffer only. MB represents mean i-cGMP levels in the presence of methylene blue $(0.01-30 \mathrm{~mm}$; no significant difference between doses). Following superfusion with Kreb's buffer, tissue slices were superfused with either (1) Kreb's only $(n=7),(2)$ methylene blue (0.01-30 $\mathrm{mM}, n=6-8 /$ dose), or (3) methylene blue (0.01-30 mM) prior to and during superfusion with SNP (100 mM) $(n=8-14 /$ dose $) . \dagger, p<0.01$ versus basal levels. ${ }^{* *}, p<0.005 ;{ }^{* * *}, p$ $<0.01$; versus SNP treatment.

hemoglobin on SNP-evoked peptide release were evaluated. Figure $6 A$ illustrates that hemoglobin significantly reduced the SNPevoked release of iCGRP at 3 and $10 \mathrm{mg} / \mathrm{ml}[F(2,28)=6.75$, $p<0.01]$. Hemoglobin alone significantly increased spontaneous iCGRP release at $10 \mathrm{mg} / \mathrm{ml}[F(2,33)=3.94, p<0.029]$. Similarly, Figure $6 B$ illustrates that hemoglobin significantly reduced the SNP-evoked release of iSP at 3 and $10 \mathrm{mg} / \mathrm{ml}$ $[F(2,29)=5.09, p<0.01]$. There was no significant difference in the basal levels of iSP release between any of the groups $[F(2,32)=1.44, p=\mathrm{NS}]$. In contrast to the release of CGRP, hemoglobin alone had no significant effect on the release of iSP at any concentration.

To evaluate whether the SNP-evoked i-cGMP increase was due to the generation of a superoxide anion from SNP, we evaluated the ability of hemoglobin to block the SNP-evoked increase in i-cGMP. Figure 7 illustrates that both doses of hemoglobin significantly reduced the ability of SNP to increase i-cGMP levels in the dorsal horn $[F(3,48)=92.59, p<0.01]$.

Photoinactivated SNP. To evaluate further whether the SNPevoked effects were dependent upon the spontaneous release of NO from SNP, we evaluated the effect of 1-week-old SNP on the release of iCGRP and iSP and on the level of $\mathrm{i}$-cGMP in the dorsal horn. Figure $8 A$ illustrates that both fresh and 7-dold SNP produced a significant increase in the release of iCGRP release when compared to basal release $[F(1,13)=119.68, p<$ $0.01]$. In addition, there was no significant difference in the amount of peptide released when the tissue was treated with fresh SNP or week-old SNP $[F(1,13)=1.38, p=$ NS $]$. Similarly, Figure $8 B$ illustrates that both fresh and week-old SNP caused a significant increase in the release of iSP when compared to basal release $[F(1,9)=361.70, p<0.01]$. In contrast to the release of iCGRP, the magnitude of the response evoked with

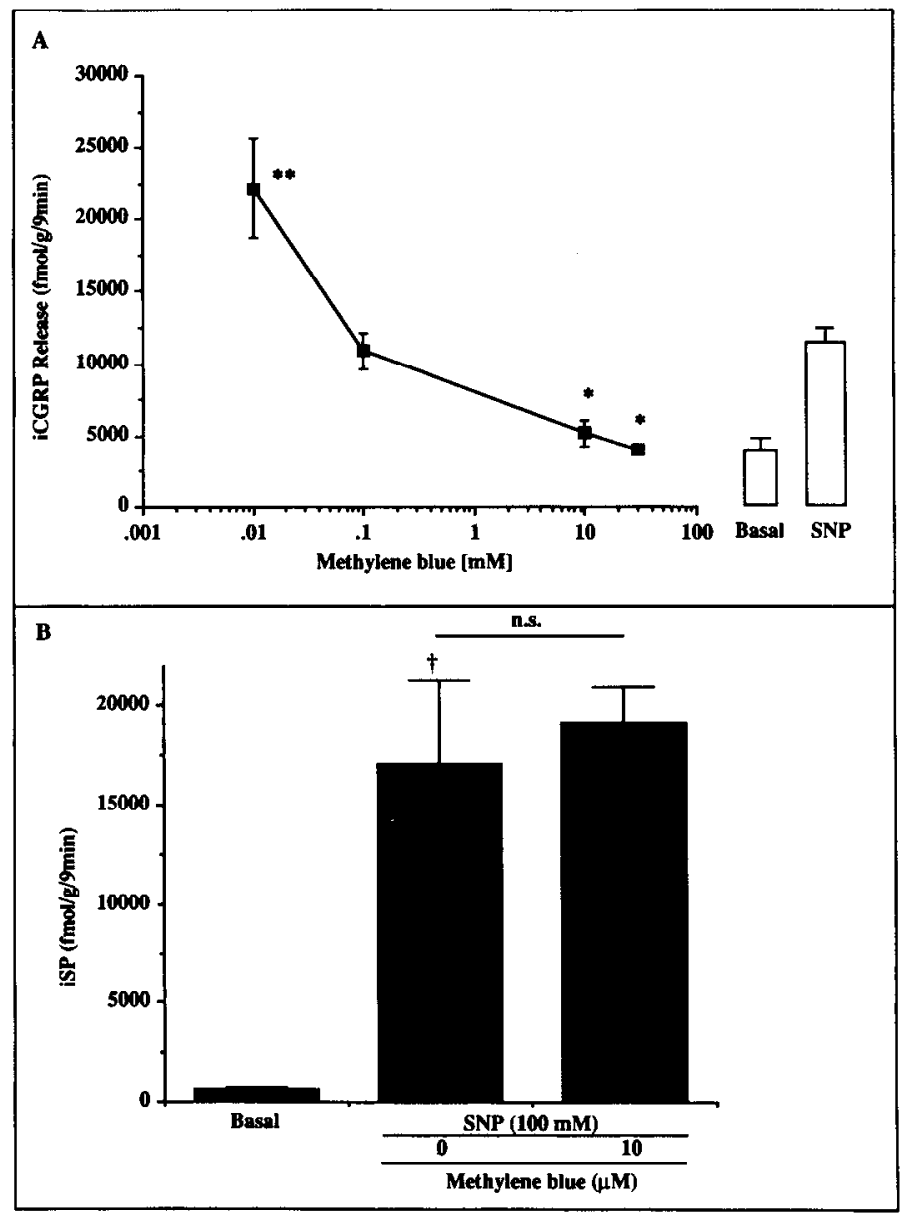

Figure 5. The effect of methylene blue on the SNP-evoked increases in the release of iCGRP $(A)$ and iSP $(B)$ from dorsal horn slices of rat spinal cord. Basal release represents the mean spontaneous peptide release in response to Kreb's buffer only. Following superfusion with Kreb's buffer, tissue slices were superfused with either (1) Kreb's buffer only $(n=7)$, (2) methylene blue only $(0.01-30 \mathrm{~mm})(n=6-8 /$ dose $),(3)$ SNP only $(100 \mathrm{~mm})(n=7)$, or (4) methylene blue $(0.01-30 \mathrm{~mm})$ prior to and during SNP $(100 \mathrm{~mm})$ stimulation $(n=8-14 /$ dose $) . \dagger, p<0.001$ versus basal release. ${ }^{*}, p<0.05 ;{ }^{* *}, p<0.01{ }^{* * *}, p<0.001$; versus SNP treatment.

week-old SNP was significantly greater than the response evoked with fresh SNP $[F(1,13)=13.28, p<0.01]$.

Sodium ferricyanide. Since SNP releases sodium ferricyanide, as well as $\mathrm{NO}$, we evaluated the ability of sodium ferricyanide to evoke the release of peptides and alter the level of i-cGMP in the dorsal horn. Sodium ferricyanide caused a significant 7.2fold increase in the release of iCGRP when compared to basal levels (Fig. $9 A ; p<0.005$ ). The magnitude of iCGRP release evoked by sodium ferricyanide was comparable to the release evoked by $100 \mathrm{~mm}$ SNP. Sodium ferricyanide caused a 2.01 fold increase in iSP release from dorsal horn slices (Fig. $9 B ; p$ $<0.05$ ). This release was not significantly different from that produced by $100 \mathrm{mM} \mathrm{SNP}[F(2,14)=2.12, p=\mathrm{NS}]$. In contrast to our results with SNP, hemoglobin did not reduce the sodium ferricyanide-evoked release of iCGRP or iSP (data not shown).

Figure 10 illustrates that both week-old SNP and sodium ferricyanide cause a significant increase in the levels of $i$-cGMP when compared to basal levels $[F(9,48)=92.59, p<0.05]$. Additionally, the levels of $\mathrm{i}$-cGMP production that were evoked 


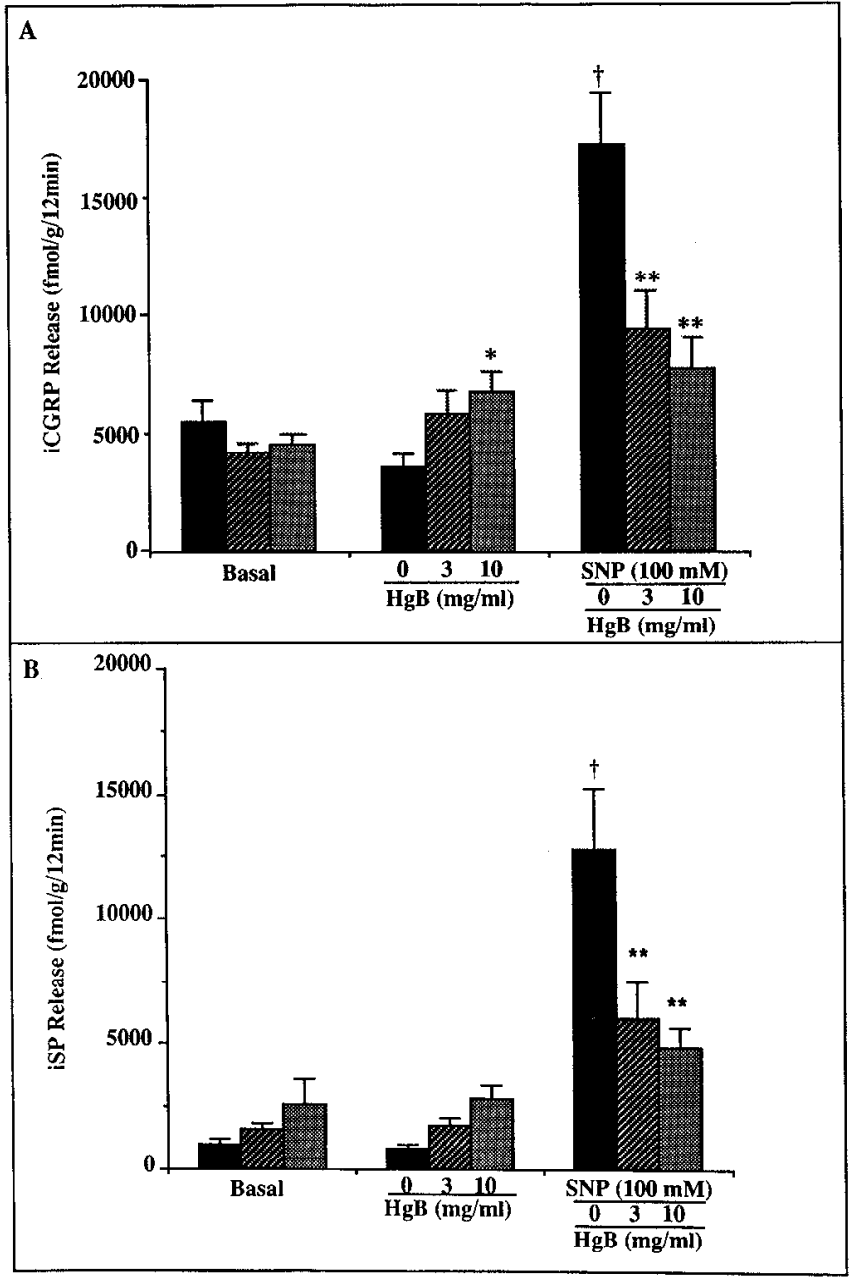

Figure 6. The effect of hemoglobin $(\mathrm{HgB})$ on SNP evoked release of iCGRP $(A)$ and iSP $(B)$. The bars labeled Basal represent the spontaneous peptide release in response to Kreb's buffer only. The bars labeled $H g B$ represent the peptide release in response to hemoglobin alone. Following superfusion with Kreb's buffer, tissues were superfused with either (1) Kreb's buffer $(n=8)$, (2) SNP (100 mM, $n=8)$, or (3) hemoglobin $(3$ or $10 \mathrm{mg} / \mathrm{ml}, n=10-12 /$ dose) prior to and during SNP $(100 \mathrm{~mm})$ treatment. $\dagger$, significant difference $(p<0.001)$ when compared to basal release. ${ }^{*}, p<0.05 ;{ }^{* *}, p<0.01$; versus SNP treatment.

by week-old SNP and SF were not significantly different when compared to each other. However, $100 \mathrm{mM}$ SNP evoked a significantly greater increase in the tissue levels of i-cGMP when compared to either week-old SNP or sodium ferricyanide $(p<$ $0.01)$.

\section{Discussion}

SNP is a potent stimulus for the release of neuropeptides and the production of $C G M P$

These data demonstrate that sodium nitroprusside is a potent stimulus for evoking the release of $i \mathrm{CGKP}$ and iSP from rat dorsal horn slices in vitro. We have demonstrated that SNP increases the release of iCGRP and iSP from spinal cord slices in a dose-related calcium-dependent manner. To our knowledge, this is the first demonstration that an NO donor evokes the release of neuropeptides in the CNS. In addition to increasing peptide release, SNP was effective in increasing the levels of $\mathrm{i}$-cGMP in dorsal horn slices. This observation is consistent with previous studies on cerebellar slices where SNP and other

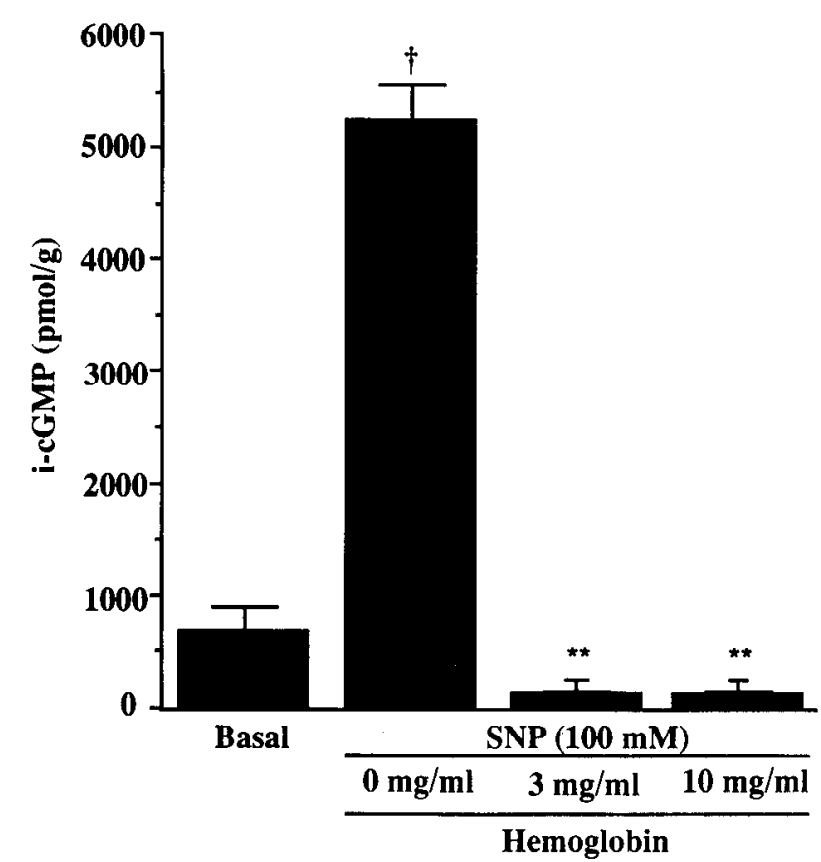

Figure 7. The effect of hemoglobin $(H g B)$ on SNP-induced i-cGMP levels. The bar labeled Basal represents the levels of i-cGMP in the presence of Kreb's buffer only. Following superfusion with Kreb's buffer, tissues were superfused with either (1) Kreb's buffer $(n=8)$, (2) SNP (100 mM, $n=8$ ), or (3) hemoglobin ( 3 or $10 \mathrm{mg} / \mathrm{ml}, n=10-12 /$ dose) prior to and during SNP ( $100 \mathrm{~mm})$ treatment. $\dagger$, significant difference $(p<0.01)$ versus basal levels. ${ }^{* *}, p<0.01$ versus SNP treatment.

NO donors stimulate increases in the levels of i-cGMP (Southam and Garthwaite, 1991). We did not discern in the present studies, however, whether SNP acts to increase peptide release and i-cGMP levels or whether it acts to inhibit the degradation of these compounds. The calcium dependence of the peptide release, however, supports the theory that SNP does increase peptide release. Regardless of the mechanism, these data demonstrate that SNP is a potent compound that increases the tissue levels of i-cGMP in dorsal horn slices and increases the levels of iCGRP and iSP in the superfusates that were collected from slices of the dorsal horn.

\section{Sites of SNP action within the dorsal horn of the spinal cord}

Our results indicate that SNP is acting on a pool of capsaicinsensitive primary afferent neurons. This hypothesis is supported by the observation that SNP pretreatment significantly reduced the ability of capsaicin to evoke peptide release. In the dorsal horn preparation, the release of iSP could be the result of activation of primary afferent neurons, interneurons, or descending tracts (Hökfelt et al., 1975; Linderoth et al., 1992). In contrast, the release of $\mathrm{iCGRP}$ in the dorsal horn can only result from the stimulation of primary afferent neurons (Chung et al., 1988). The present results, however, do not identify the actual mechanism by which SNP inhibits capsaicin-evoked peptide release. It is possible that SNP blocks the nonselective cation channel activated by capsaicin in certain populations of primary afferent neurons (Takaki et al., 1991). Alternatively, SNP may act to desensitize certain primary afferent neurons to capsaicin stimulation or deplete stores of peptides in capsaicin-sensitive neurons. It is also possible that SNP interferes with the binding of capsaicin on primary afferent neurons. Although further stud- 


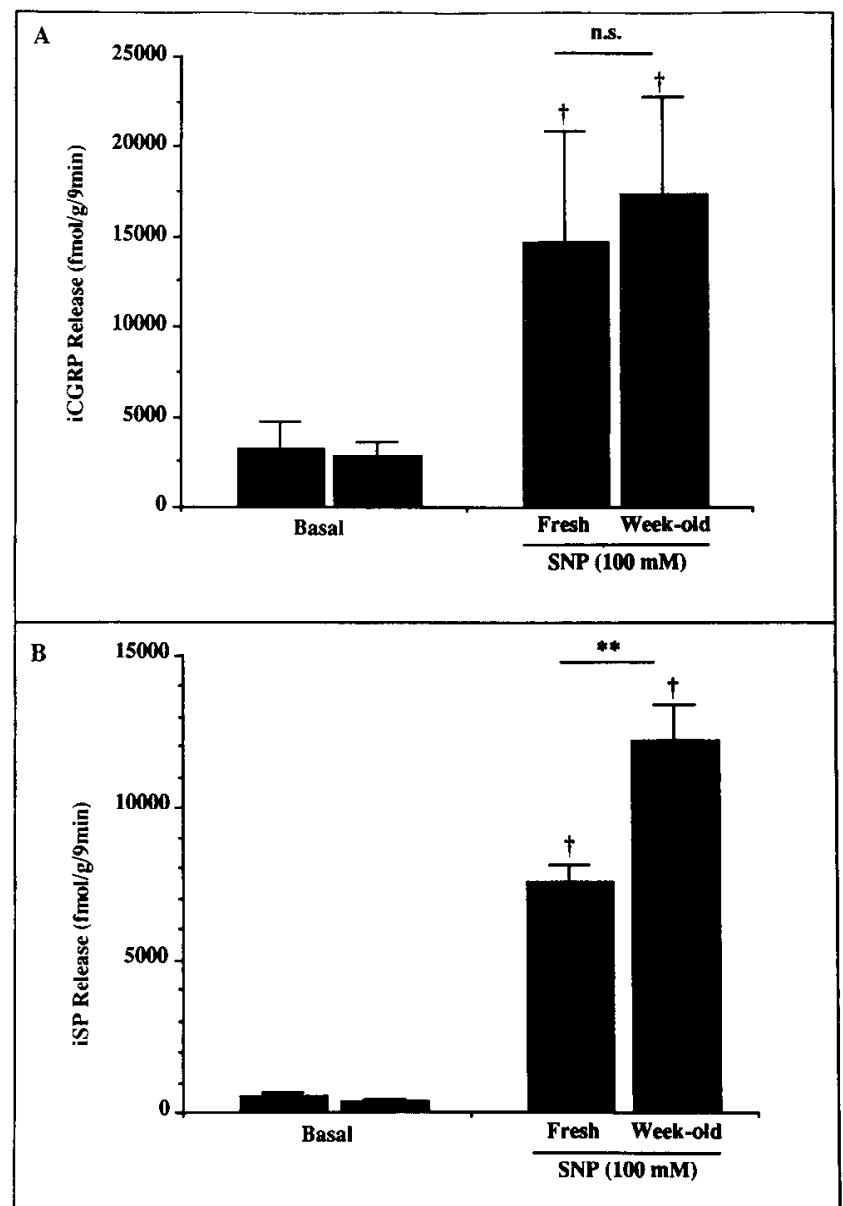

Figure 8. The effect of 7-d-old SNP on the release of iCGRP $(A)$ and iSP $(B)$ from dorsal horn slices. The bar labeled Basal (peptide release in response to Kreb's buffer only) represents the mean peptide release from both treatment groups (no significant difference between groups). Following superfusion with Kreb's buffer, tissue slices were superfused with either (1) Kreb's buffer $(n=8)$, (2) fresh SNP $(100 \mathrm{mM}, n=6)$, or (3) 7-d-old SNP (100 mM, $n=7$ ). $\dagger, p<0.01$ versus basal release. ** $p<0.01$ (fresh vs week-old SNP).

ies will be required to elucidate the precise mechanism(s) by which SNP pretreatment inhibits capsaicin-evoked peptide release, the present results indicate that SNP and capsaicin activate an overlapping pool of primary afferent neurons. Additionally, the similarity in $A_{50}$ values for SNP-evoked iCGRP and iSP release suggests that SNP is acting on neurons with similar response properties to chemical stimuli. These results suggest that iCGRP and iSP may be simultaneously released from the same neuron.

\section{Correlation between peptide release and the level of $i-c G M P$ in} the dorsal horn

Our data suggest that there is a positive association between increasing levels of i-cGMP in the dorsal horn and increasing the release of iCGRP from slices of the dorsal horn (since our RIA for iSP would not perform in the presence of higher concentrations of methylene blue, we are limiting this conclusion only to the release of iCGRP). For example, $100 \mathrm{~mm}$ SNP stimulates increases in the release of iCGRP and in the level of $\mathrm{i}$-cGMP in the dorsal horn. Moreover, certain doses of methylene blue are efficacious in decreasing the SNP-evoked release

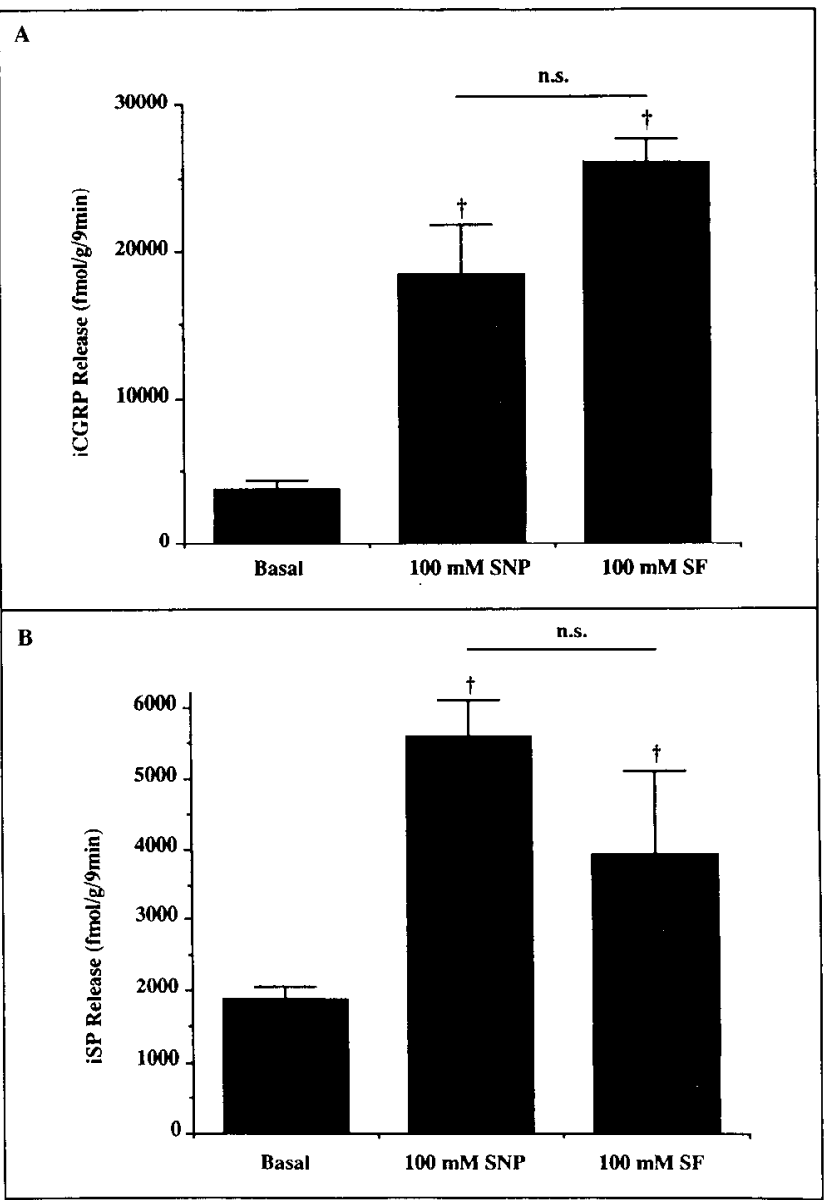

Figure 9. The effect of sodium ferricyanide $(S F)$ on the release of iCGRP $(A)$ and iSP $(B)$ from dorsal horn slices. The bar labeled Basal (peptide release in response to Kreb's buffer only) represents the mean peptide release from both trcatment groups (no significant difference between groups). Following superfusion with Kreb's buffer, tissue slices were superfused with either Kreb's buffer $(n=8)$, (2) SNP (100 mM, $n$ $=4-6$ ), or (3) sodium ferricyanide (100 mM, $n=4-6)$. $\dagger, p<0.01$ versus basal release.

of iCGRP and in reducing the SNP-evoked increase in the level of $i-c G M P$ in the dorsal horn. Finally, doses of hemoglobin that are efficacious in reducing SNP-evoked peptide release completely abolish the SNP-evoked increase in the level of i-cGMP in the dorsal horn. Our data indicate, however, that the strength of the association between increasing levels of i-cGMP and increased release of iCGRP in the dorsal horn is equivocal, since there are instances when an association between these two factors is not apparent. For example, $30 \mathrm{~mm}$ is the $A_{50}$ concentration for the effect of SNP on the release of iCGRP and iSP from the dorsal horn. In contrast, $30 \mathrm{~mm}$ SNP has no effect on the basal level of iCGMP in the dorsal horn. Additionally, when $10 \mu \mathrm{M}$ methylene blue is administered to the dorsal horn slices, there is a reduction in the SNP-evoked increase in the level of i-cGMP, yet the release of iCGRP is significantly increased. Finally, photoinactivated SNP and sodium ferricyanide were equally potent in their ability to increase the release of iCGRP and iSP when compared to fresh SNP, while neither of these compounds was as potent as fresh SNP in their ability to increase the level of i-cGMP in the dorsal horn. Taken together, these data suggest that there is a positive association between increased release of iCGRP and increasing levels of $\mathrm{i}$-cGMP in the dorsal horn; 


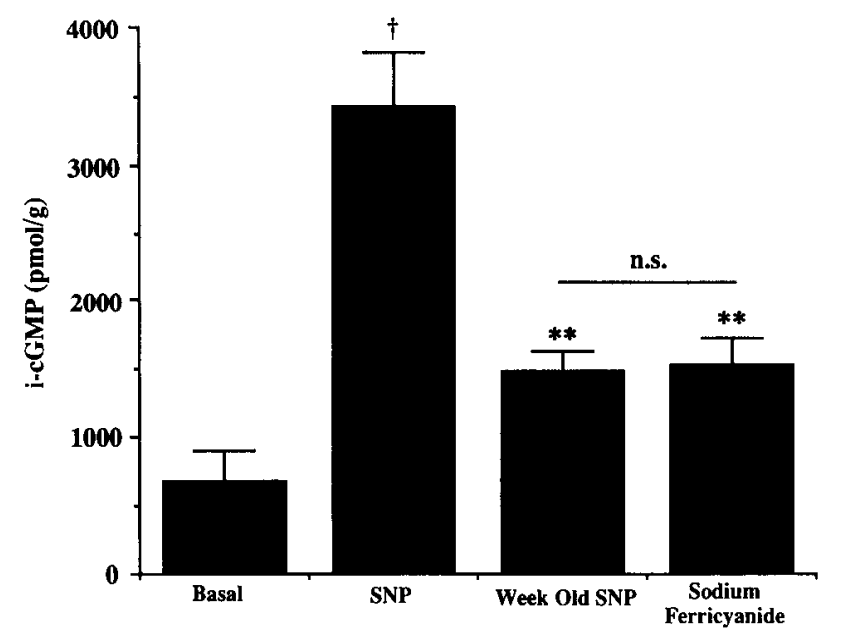

Figure 10. The effect of 7-d-old SNP and sodium ferricyanide on the tissue levels of i-cGMP in the dorsal horn. The bar labeled Basal (icGMP levels in response to Kreb's buffer only) represents the mean levels from all treatment groups (no significant difference between groups). Following superfusion with Kreb's buffer, tissue slices were superfused with either (1) Kreb's buffer $(n=16)$, (2) SNP (100 mM, $n=10-12)$, (3) 7-d-old SNP (100 mM, $n=7$ ), or (4) sodium ferricyanide (100 mM, $n=6)$. $\dagger$, significant difference $(p<0.01)$ when compared to basal levels. ${ }^{* *}, p<0.01$ when compared to basal levels.

however, the strength of this association remains to be elucidated.

\section{SNP, NO, and hyperalgesia}

The present data demonstrate that SNP acts to evoke the release of iCGRP and iSP from dorsal horn slices. These data are consistent with previous studies that demonstrate that SNP causes hyperalgesia following intrathecal administration in mice (Kitto et al., 1992) and with the hypothesis that the increased release of these peptides may serve as biochemical markers for hyperalgesia (Garry and Hargreaves, 1992). Therefore, these data suggest that the release of iCGRP, iSP, or other related cofactors may be required for the development and/or maintainence of SNP-evoked hyperalgesia. In addition, the fact that SNP increases the production of $\mathrm{i}-\mathrm{cGMP}$ in the dorsal horn is consistent with previous behavioral studies suggesting that an NO-cGMP pathway is involved in the maintainence of hyperalgesia (Kitto et al., 1992; Meller et al., 1992a,b; Meller and Gebhart, 1993).

Although a source of endogenous NO has not been defined in these studies, immunohistochemical studies have localized the NO-synthesizing enzyme to the superficial dorsal horn (Bredt et al., 1991). Since NO can readily diffuse to its site of action, it is conceivable that an endogenous source of $\mathrm{NO}$ is available to act upon primary afferent neurons. Therefore, it is possible that an endogenous NO system exists in the dorsal horn, which may play a role in the development or maintainence of nociception and hyperalgesia.

\section{SNP has NO-dependent and-independent effects}

$N O$-dependent cffects of SNP. It has previously been demonstrated that the NO scavenger hemoglobin blocks SNP-evoked hyperalgesia (Kitto et al., 1992). Our data support these behavioral findings, since hemoglobin reduced the ability of SNP to evoke peptide release [we did observe that hemoglobin $(10 \mathrm{mg} /$ ml) caused a slight increase in the basal release of iCGRP, although this concentration of hemoglobin significantly reduced the SNP-evoked increase in the release of iCGRPI. In addition, we observed that hemoglobin was efficacious in suppressing SNP-evoked increases in i-cGMP levels. These data suggest that one mechanism of action of SNP is dependent upon the release of NO from the drug. While hemoglobin scavenges NO, however, it has also been demonstrated to scavenge carbon monoxide, which is also generated in neural tissue and regulates cGMP (Vcrma ct al., 1993). However, carbon monoxide is not formed by SNP dissolution, suggesting that the effects of hemoglobin are most likely due to the scavenging of NO.

$N O$-independent effects of SNP. Upon further evaluation of the NO-dependent activity of SNP, however, we observed that SNP has effects that cannot be attributed to the release of NO by the drug. In support of this conclusion, we observed that both sodium ferricyanide and a solution of SNP that has been photolytically inactivated can still evoke peptide release and stimulate the production of i-cGMP in dorsal horn slices. In fact, photoinactivated SNP was more potent in evoking the release of iSP than was fresh SNP. Interestingly, inactivated SNP and sodium ferricyanide were equipotent in stimulating the production of i-cGMP. These data suggest that the ability of the inactivated SNP to increase i-cGMP levels was due to its sodium ferricyanide content. However, both of these agents were less efficacious in stimulating the production of i-cGMP than was a fresh solution of SNP, suggesting that NO-dependent and NO-independent factors contribute to the effect of SNP on the levels of $i-c G M P$ in the dorsal horn. Recent studies in cerebellar slices support the observation that SNP has NO-independent activity (Benz et al., 1992; Stout and Woodward, 1992). From these results, we conclude that there are NO-dependent and an NO-independent pathways that facilitate the observed increases in $\mathrm{i}-\mathrm{cGMP}$ levels and neuropeptide release in the dorsal horn.

In summary, we conclude that SNP is a potent stimulus for evoking the release of iCGRP and iSP from dorsal horn slices. Furthermore, our results suggest that SNP is acting on a pool of capsaicin-sensitive primary afferent neurons. Sodium nitroprusside is also a potent stimulus for evoking increases in i-cGMP in the dorsal horn. Our data suggest that there is an association between i-cGMP levels and iCGRP release in the dorsal horn, although the strength of this association remains undetermined. In addition, these data demonstrate that SNP has NO-dependent and NO-independent mechanisms of action in the dorsal horn for increasing tissue levels of i-cGMP and evoking the release of iCGRP and iSP.

\section{References}

Aanonsen LM, Wilcox GL (1987) Nociceptive action of excitatory amino acids in the mouse: effects of spinally administered opioids, phencyclidine and agonists. I Pharmacol Exp Ther 243:9-19.

Bauer MB, Murphy S, Gebhart GF (1992) Capsaicin stimulates cGMP via nitric oxide in dorsal root ganglion cell cultures. Soc Neurosci Abstr 18:689.

Benz AM, Izumi Y, Clifford DB, Zorumski CF, Olney JW (1992) Neurotoxic effects of sodium nitroprusside in rat hippocampal slices. Soc Neurosci Abstr 18:645.

Bossut D, Frenk H, Mayer DJ (1988) Is substance $\mathrm{P}$ a primary afferent neurotransmitter for nociceptive input? II. Spinalization does not reduce and intrathecal morphine potentiates behavioral responses to substance P. Brain Res 455:232-239.

Bredt DS, Snyder SH (1989) Nitric oxide mediates glutamate-linked enhancement of cGMP levels in the cerebellum. Proc Natl Acad Sci USA 86:9030-9033.

Bredt DS, Snyder SH (1992) Nitric oxide: a novel neuronal messenger Neuron 8:8-11.

Bredt DS, Glatt CE, Hwang PM, Fotuhi M, Dawson TM, Snyder SH 
(1991) Nitric oxide synthase protein and mRNA are discretely localized in neuronal populations of the mammalian CNS together with NADPH diaphorase. Neuron 7:615-624.

Campbell JN, Meyer RA (1986) Primary afferents and hyperalgesia In: Spinal afferent processing (Yaksh TL, ed). New York: Plenum.

Chapman PF, Atkins CM, Allen MT, Haley JE, Steinmetz JE (1992) Inhibition of nitric oxide synthesis impairs two different forms of learning. Neuroreport 3:567-570.

Chung K, Lee WT, Carlton SM (1988) The effects of dorsal rhizotomy and spinal cord isolation on calcitonin gene-related peptide-labeled terminals in the rat lumbar dorsal horn. Neurosci Lett 90:27-32.

Coderre TJ, Melzack R (1991) Central neural mediators of secondary hyperalgesia following heat injury in rats: neuropeptides and excitatory amino acids. Neurosci Lett 131:71-74.

Davies J, Watkins JC (1983) Role of excitatory amino acid receptors in mono- and polysynaptic excitation in cat spinal cord. Exp Brain Res 49:280-290.

Fitzgerald M (1983) Capsaicin and sensory neurons-a review. Pain 15:109-130.

Galeazza MT, Stucky CL, Seybold VS (1992) Changes in [125I]hCGRP binding in rat spinal cord in an experimental model of acute, peripheral inflammation. Brain Res 591:198-208.

Garry MG, Hargreaves KM (1992) Enhanced release of immunoreactive CGRP and substance $\mathbf{P}$ from spinal dorsal horn slices occurs during carrageenan inflammation. Brain Res 582:139-142.

Garthwaite J (1991) Glutamate, nitric oxide and cell-cell signalling in the nervous system. Trends Neurosci 14:60-67.

Grubb BD, Stiller RU, Schiable H-G (1993) Dynamic changes in the receptive field properties of spinal cord neurons with ankle input in rats with chronic unilateral inflammation in the ankle region. Exp Brain Res 92:441-452.

Haley JE, Dickenson AH, Schachter M (1992a) Electrophysiological evidence for a role of nitric oxide in prolonged chemical nociception in the rat. Neuropharmacology 31:251-258.

Haley JE, Wilcox GL, Chapman PF (1992b) The role of nitric oxide in hippocampal long-term potentiation. Neuron 8:211-216.

Hökfelt TJ, Kellerth O, Nilsson O, Pernow B (1975) Substance P: localization in the CNS and in some primary sensory neurons. Science 190:889-890.

Hylden JLK, Nahin RL, Traub RJ, Dubner R (1989) Expansion of receptive fields of spinal lamina $I$ projection neurons in rats with unilateral adjuvant-induced inflammation: the contribution of dorsal horn mechanisms. Pain 37:229-243.

Kawamura M, Kuraishi Y, Minami M, Satoh M (1989) Antinociceptive effect of intrathecally administered antiserum against calcitonin gene-related peptide on thermal and mechanical noxious stimuli in experimental hyperalgesic rats. Brain Res 497:199-203.

Kitto KF, Haley JE, Wilcox GL (1992) Involvement of nitric oxide in spinally mediated hyperalgesia in the mouse. Neurosci Lett 148: $1-5$.

Knowles RG, Palacios M, Palmer RMJ, Moncada S (1990) Kinetic characteristics of nitric oxide synthase from rat brain. Biochem $\mathrm{J} 269$ : 207-210.

Kolhkear R, Meller ST, Gebhart GF (1992) NMDA receptor-mediated biphasic effects on thermal nociceptive spinal transmission. Soc Neurosci Abstr 18:1024.

Linderoth B, Gazelius B, Franck J, Brodin E (1992) Dorsal column stimulation induces release of serotonin and substance $P$ in the cat dorsal horn. Neurosurgery 31:289-296.

Malenka KC, Kauer JA, Zucker RS, Nicoll RA (1988) Postsynaptic calcium is sufficient for potentiation of hippocampal synaptic transmission. Science 242:81-84.

Malenka RC, Kauer JA, Perkel DJ, Mauk MD, Kelly PT, Nicoll RA, Waxham MN (1989) An essential role for postsynaptic calmodulin and protein kinase activity in long-term potentiation. Nature 340 : $554-557$.

McCall T, Vallance P (1992) Nitric oxide takes centre-stage with newly defined roles. Trends Pharmacol 13:1-6.

Meller ST, Gebhart GF (1993) Nitric oxide (NO) and nociceptive processing in the spinal cord. Pain 52:127-136.

Meller ST, Dykstra C, Geblart GF (1992a) Production of endogenous nitric oxide and activation of soluble guanylate cyclase are required for $N$-methyl-D-aspartate-produced facilitation of the nociceptive tailflick reflex. Eur J Pharmacol 214:93-96.

Meller ST, Pechman PS, Gebhart GF, Maves TJ (1992b) Nitric oxide mediates the thermal hyperalgesia produced in a model of neuropathic pain in the rat. Neuroscience 50:7-10.

Menetrey D, Besson J-M (1982) Electrophysiological characteristics of dorsal horn cells in rats with cutaneous inflammation resulting from chronic arthritis. Pain 13:343-364.

Moncada S, Palmer RM, Higgs EA (1991a) Nitric oxide: physiology, pathophysiology, and pharmacology. Pharmacol Rev 43:109-142.

Moncada S, Rees DD, Schulz R, Palmer RM (1991b) Development and mechanism of a specific supersensitivity to nitrovasodilators after inhibition of vascular nitric oxide synthesis in vivo. Proc Natl Acad Sci USA 88:2166-2170.

Murray CW, Cowan A, Larson AA (1991) Neurokinin and NMDA antagonists (but not a kainic acid antagonist) are antinociceptive in the mouse formalin model. Pain 44:179-185.

Nanayama T, Kuraishi Y, Ohno II, Satoh M (1989) Capsaicin-induced release of calcitonin gene-related peptide from dorsal horn slices is enhanced in adjuvant arthritic rats. Neurosci Res 6:569-572.

Oku R, Satoh M, Fujii N, Otaka A, Yajima J, Takagi H (1987a) Calcitonin gene-related peptide promotes mechanical nociception by potentiating release of substance $\mathrm{P}$ from the spinal dorsal horn in rats. Brain Res 403:350-354.

Oku R, Satoh M, Takagi H (1987b) Release of substance P from the spinal dorsal horn is enhanced in polyarthritic rats. Neurosci Lett 74 315-319.

Otsuka M, Yanagisawa M (1990) Pain and neurotransmitters. Cell Mol Neurobiol 10:293-302.

Satoh M, Kuraishi Y, Kawamura M (1992) Effects of intrathecal antibodies to substance $P$, calcitonin gene-related peptide and galanin on repeated cold stress-induced hyperalgesia: comparison with carrageenan-induced hyperalgesia. Pain 49:273-278.

Schiable H-G, Schmidt RF, Willis WD (1987) Enhancement of the responses of ascending tract cells in the cat spinal cord by acute inflammation of the knee joint. Exp Brain Res 66:489-499.

Schiable H-G, Jarrott B, Hope PJ, Duggan AW (1990) Release of immunoreactive substance $P$ in the spinal cord during development of acute arthritis in the knee joint of the cat: a study with antibody microprobes. Brain Res 529:214-223.

Simone DA (1992) Neural mechanisms of hyperalgesia. Curr Opin Neurobiol 2:479-483.

Simone DA, Sorkin LS, Oh U, Chung JM, Owens C, LaMotte RH, Willis WD (1991) Neurogenic hyperalgesia: central neural correlates in responses of spinothalamic tract neurons. J Neurophysiol 66:228246.

Sluka KA, Dougherty PM, Sorkin LS, Willis WD, Westlund KN (1992) Neural changes in acute arthritis in monkeys. III. Changes in substance $P$, calcitonin gene-related peptide and glutamate in the dorsal horn of the spinal cord. Brain Res Rev 17:29-38.

Southam E, Garthwaite J (1991) Comparative effects of some nitric oxide donors on cyclic GMP levels in rat cerebellar slices. Neurosci Lett 130:107-111.

Southam E, East SJ, Garthwaite J (1991) Excitatory amino acid receptors coupled to the nitric oxide/cyclic GMP pathway in rat cerebellum during development. J Neurochem 56:2072-2081.

Stout AK, Woodward JJ (1992) Inhibition of $N$-methyl-D-aspartatestimulated neurotransmitter release by sodium nitroprusside is not due to nitric oxide. Soc Neurosci Abstr 18:256.

Sun XF, Larson AA (1991) Behavioral sensitization to kainic acid and quisqualic acid in mice: comparison to NMDA and substance $P$ responses. J Neurosci 11:3111-3123.

Takaki M, Kikuta A, Nakayama S (1991) Ruthenium red antagonism of the effects of capsaicin mediated by extrinsic sensory nerves on myenteric plexus neurons of the isolated guinea-pig ileum. Brain Res 551:87-93

Treede RD, Meyer RA, Raja SN, Campbell JN (1992) Peripheral and central mechanisms of cutaneous hyperalgesia. Prog Neurobiol 38: $397-426$.

Tsai HY, Lin JG, Inoki R (1989) Further evidence for possible analgesic mechanism of electroacupuncture: effects on neuropeptides and serotonergic neurons in rat spinal cord. Jpn J Pharmacol 49:181185.

Verma A, IIirsch DJ, Glatt CE, Ronnett GV, Synder SH (1993) Carbon monoxide: a putative neural messenger. Science 25:381-384.

Waldman S, Murad F (1987) Cyclic GMP synthesis and function. Pharmacol Rev 39:163-195. 